\title{
Applications of Artificial Neural Network in Determining the Mechanical Properties of Melon Fruits
}

\author{
Babawuya $^{1 *}$ A., Z. D. Osunde ${ }^{2}$, I. O. Sadiq ${ }^{1}$ and Eramus C. $\mathrm{U}^{3}$. \\ 1. Mechanical Engineering Department, Federal University of Technology, Minna. \\ 2. Agricultural and Bio-resources Engineering, Federal University of Technology, Minna. \\ 3. Mechanical Engineering Department, Waziru Umaru Federal Polytechnic, Birnin Kebbi.
}

\begin{abstract}
The paper presents the application of artificial neural network (ANN) in predicting some mechanical properties of Melon fruits. There is no established numerical relation between the physical properties and the mechanical properties of melon fruits. The physical data were obtained experimentally for 120 melon fruits. A feedforward backward propagation (ff-BP) architecture was developed and used to estimate the mechanical properties of the Melon fruits from the measured physical properties. A Levenberg-Marquoardt (LM) optimization was used to train the 4-5-5-1 Multi-layer Perceptron (MLP) network and root mean square error (RMSE) was used as performance criteria. The physical properties were trained using MATLAB Neural Network Toolbox and the results compared with experimental values. It was observed that the ANN's predicted values and the experimental results agreed upto 95\%. The network predicts a maximum shear force of 400.76N and a minimum $206.48 \mathrm{~N}$. and a best evaluation performance was reached after tepoch three (3).
\end{abstract}

Keywords: Load-deflection, Neurons, Melon Seed, Melon fruits, MLP network.

\section{Introduction}

Melon fruits are very important vegetable in Nigeria, it is used for soup and the oil from melon fruits has the potential for domestic and industrial use. The mechanical properties if of melon fruits is very necessary to design the separating, hulling and handling equipment, as well as designing harvest, post harvest handling, processing devices and transportation of the product. Also the mechanical properties is an indexes used in the determination of the quality measurement of fruits. Melon fruits cannot be machined to a standard test piece, therefore it require a non-conventional method to accurately estimate the desire mechanical properties.

Frequently, system/process phenomena occur where it is difficult to establish the relationship between the dependent variables and independent variables, (Ismail, etal, 2012). In such cases it will be difficult to map the behaviour of a system/process with mathematical model, and even when solutions found, most times such mathematical model is usually complex, non-linear and parallel. There is no established numerical relation between the physical properties and the mechanical properties of melon fruits. Therefore artificial neural network provides a better way of handling this kind of problem.

\subsection{ANN and Its Limitations}

An artificial neural network is a learning system based on computational technique that can simulate the neurological processing ability of the human brain and can be applied to quantify a nonlinear relationship between dependent and independent variables by means of iterative training of data obtained

\subsection{Objectives}

The objective of this work is to use measured physical properties such as ratio of major diameter, minor diamter, weight and volume of melon seeds and mechanical properties- shear strength and deflection to map the mechanical properties of melon fruits. The physical and mechanical properties are independent variables and have not being expressed mathematically or empirically. from a designed experiment or source. (Svetlena, etal 2003).

ANN is a computational model inspired in the natural neurons. The natural neurons receive signal through synapse located on the dendrites or membrane of the neuron. When the signal received are strong enough and emits a signal through axon, this signal might be sent to another synapse and might activate other neurons, (Ismail, 2012). Comparisons of biological and artificial neuron are shown in the Table 1 ANN requires a target (or sample) data to be able to predict or map data. It also requires a careful or optimal network selection or design. 
Table 1: Comparison of Natural and Artificial Neurons

\begin{tabular}{|c|c|c|}
\hline & Natural Neuron & Artificial Neuron \\
\hline Structure & A Motor Neuron & 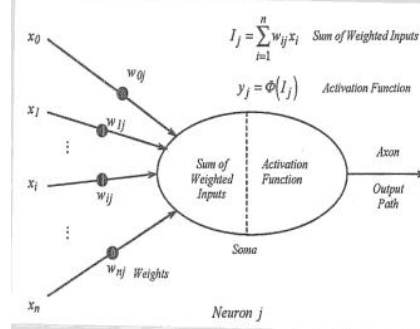 \\
\hline Components & $\begin{array}{ll}\text { - } & \text { Soma } \\
\text { - } & \text { Dendrite } \\
\text { - } & \text { Axon } \\
\text { - } & \text { Synapse } \\
\end{array}$ & $\begin{array}{ll}- & \text { Neuron } \\
- & \text { Input, (x). } \\
- & \text { Output, (y). } \\
- & \text { Weight, (w). }\end{array}$ \\
\hline
\end{tabular}

Source:

\subsection{Experimentation}

\section{Research Methodology}

The melon fruits were grouped into five (5) groups of four (4) fruits each depending on their sizes, (i.e group A,B,C,D and E). Group A1-A4 represents the smallest sizes, while group E1-E4 represents the largest sizes. The physical properties taken includes: major diameter, minor diameter, weight and volume of the melon fruits.

The mechanical properties were measured at National Center for Agricultural Mechanization (NCAM), Ilorin-Nigeria. Universal testing machine (Testmetric series 500-532) was used to load the melon fruits to a point of rupture and a deflection-load data was obtained.

Table 2: Shows The Instrument/Materials Used For The Experimental.

\begin{tabular}{lll}
\hline S/No & Instruments/Materials & Qty \\
\hline $\mathbf{1}$ & University testing Machine & 1 \\
& (Testometric series 500-532) & \\
$\mathbf{2}$ & Measuring cylinder & 2 \\
$\mathbf{3}$ & Vernier callipers & 1 \\
$\mathbf{4}$ & Containers & 3 \\
$\mathbf{5}$ & Weighting machine & 1 \\
$\mathbf{6}$ & Masking tape & 1 \\
$\mathbf{7}$ & Melon fruits & 20 \\
\hline
\end{tabular}

Table 3: Physical Properties of Melon fruits measured.

\begin{tabular}{ccccccc}
\hline Groups & $\begin{array}{c}\text { Major Dia. } \\
(\mathbf{m m})\end{array}$ & $\begin{array}{c}\text { Minor Dia. } \\
(\mathbf{m m})\end{array}$ & $\begin{array}{c}\text { Weight } \\
(\mathbf{g})\end{array}$ & $\begin{array}{c}\text { Volume } \\
(\mathbf{m L})\end{array}$ & $\begin{array}{c}\text { Yield Shear Load } \\
(\mathbf{N})\end{array}$ & $\begin{array}{c}\text { Deformation } \\
(\mathbf{m m})\end{array}$ \\
\hline $\mathbf{A 3}$ & 143.5 & 140 & 1300 & 1450 & 364 & 24.724 \\
A4 & 143 & 141 & 1300 & 1450 & 297.8 & 21.76 \\
B3 & 105 & 114 & 650 & 680 & 484.5 & 23.088 \\
B4 & 103 & 111 & 625 & 590 & 529.4 & 26.44 \\
C3 & 97 & 103 & 425 & 450 & 608 & 27.43 \\
C4 & 92.5 & 103 & 475 & 480 & 366.5 & 20.524 \\
D3 & 84.5 & 91 & 325 & 340 & 310.6 & 24.02 \\
D4 & 82 & 93 & 325 & 320 & 277.4 & 18.2 \\
E3 & 72 & 74.5 & 175 & 150 & 167.9 & 15.96 \\
E4 & 66 & 72.5 & 175 & 145 & 167.77 & 14.56 \\
\hline
\end{tabular}

\subsection{Design of Neural Network}

Table 3, summarises the experimental data from Kwaya, (2008). The physical properties (major diameter, height, weight and volume) of the melon measured along the mechanical properties (shear force and deflection) were used to design neural network. These measured physical properties form the input, while the measured mechanical properties are the target for neural network for prediction. A three layer feed-forward-BP algorithms was applied to calculate the best estimation of the compressive force, shear force and deflection using newff function in MATLAB. The training data set has 120 pattern and the network is trained for 300 epochs. A Levenberg-Marquoardt (LM) optimization was used to train the 4-5-5-1 MLP network.

According (Seyed, etal 2001), (Hayati, etal 2007), (Obodeh, etal 2009) MLP outperform the other training algorithms in this type of data set, especially simple gradient descent and other conjugate gradient methods. The numbers of neurons in the input and out layers are determined generally by the input and output parameters, in this case 4 and 1 . The number of neurons in the hidden layer was optimally chosen to obtained 
best estimated. A 4-5-5-1 network topology gives the optimal values of the estimate and is shown in Fig 1. The neural network parameters are listed in table 5.

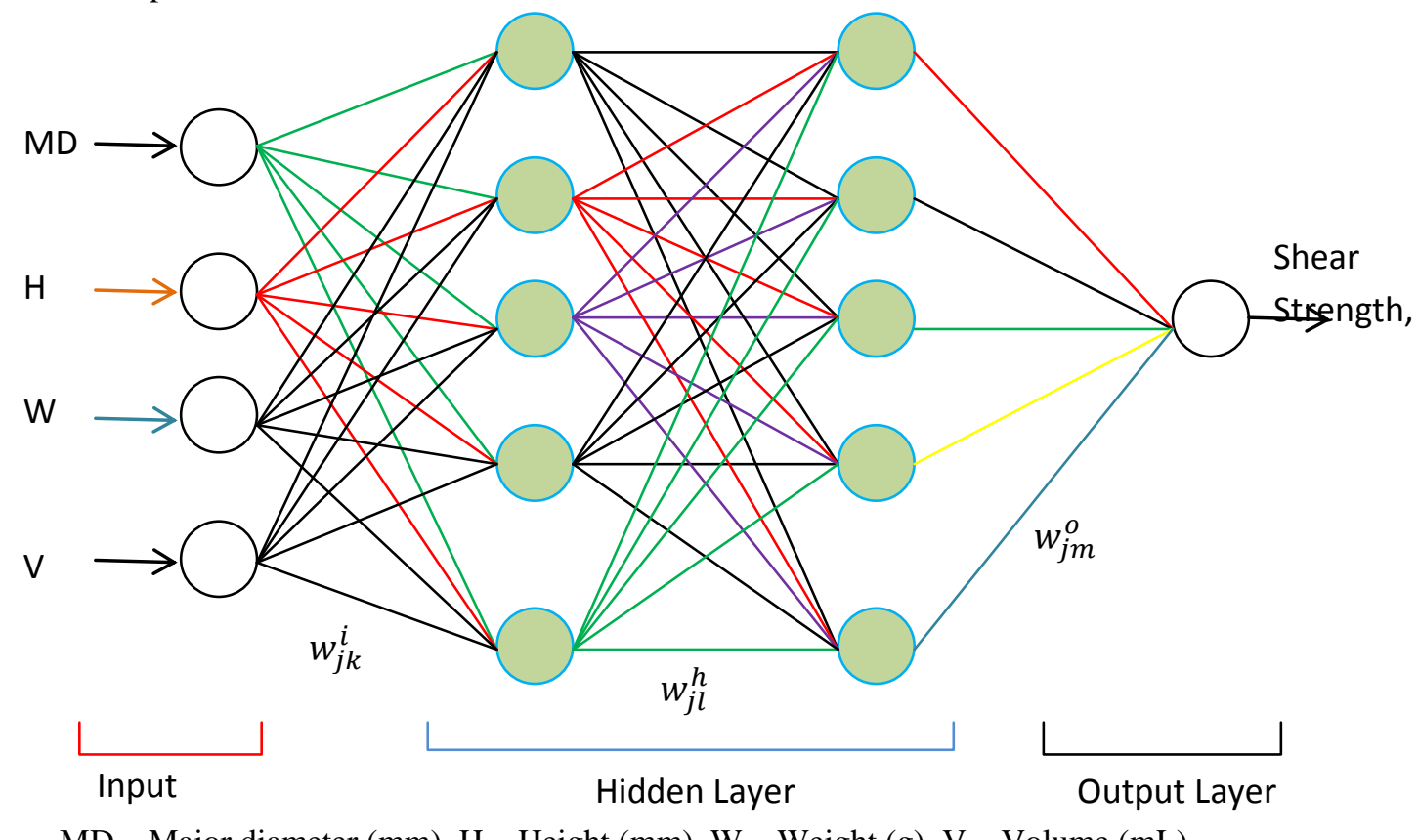

MD - Major diameter (mm), H - Height (mm), W - Weight (g), V - Volume (mL).

Figure 1: Network configuration with 4-5-5-1 for the shear load and deflection prediction.

Table 5: Optimal Characteristics of the Feedforward BP Network

\begin{tabular}{lc}
\hline \multicolumn{1}{c}{ NN } & MLP \\
\hline Number of hidden layer & 2 \\
Number of neurons in the input layer & 4 \\
Number of neuron in the & 5 \\
$1^{\text {st }}$ hidden layer & \\
Number of neuron in the & 5 \\
$2^{\text {nd }}$ hidden layer & \\
Number of neuron in the & 1 \\
output layer & \\
Learning rate & 0.5 \\
Number of epoch & 300 \\
Adapt learning function & Trainln \\
Training & 0.00001 \\
\hline
\end{tabular}

\subsection{Performance Criteria}

The performance of the model was evaluated by a set of test data using the root mean square error (RMSE) and the coefficient of determination between the predicted and experimental data. Equation 1 shown the RMSE (Turgey, etal 2010):

$$
\square \square \square \notin \sqrt{\frac{1}{\square} \sum_{\square=1}^{\square}\left(\square_{\square \square \square \square}-\square \square \square\right)^{2}}
$$

Where:

$$
\begin{aligned}
& \square_{\square \square}=\text { Observed value } \\
& \square_{\square \square \square}=\text { predicted value }
\end{aligned}
$$

$$
\square=\square \square \square \square \square \square \square \square \square \square \square \square \square \square \square \square \square
$$

\section{Simulation Results And Discussion}

A MATLAB code was developed and used to train and simulate the NN structure in figure 1.1., in other to predict the yield shear strength and equivalent deflection at yield rupture. Table 6 shows results of the simulated NN model for the prediction of the shear strength of the melon fruits, this includes the experimental data (Kwaya, 2008), ANN predicted values, RMSE value, average, Maximum and the minimum values 
Table 6: ANN versus experimental results and their analysis

\begin{tabular}{llllllll}
\hline GROUPS & $\begin{array}{l}\text { Exp. yield } \\
\text { shear load }\end{array}$ & $\begin{array}{l}\text { Predicted Yield } \\
\text { Shear force }\end{array}$ & $\begin{array}{l}\text { Exp. } \\
\text { Deflection }\end{array}$ & $\begin{array}{l}\text { Predicted } \\
\text { Deflection }\end{array}$ & Yield & RMSE1 & RMSE2 \\
\hline A3 & 364 & 306.83 & 24.724 & 14.82 & 57.607 & 9.9037 \\
A4 & 297.8 & 306.83 & 21.76 & 14.832 & -9.027 & 6.9279 \\
B3 & 484.5 & 510.12 & 23.088 & 15.817 & 25.62 & 7.2706 \\
B4 & 529.4 & 548.25 & 26.44 & 16.307 & -18.85 & 10.133 \\
C3 & 608 & 576.58 & 27.43 & 17.128 & 31.418 & 10.302 \\
C4 & 366.5 & 518.44 & 20.524 & 16.582 & -151.9 & 3.9418 \\
D3 & 310.6 & 399.34 & 24.02 & 17.888 & -88.74 & 6.1317 \\
D4 & 277.4 & 361.61 & 20.922 & 18.471 & -84.21 & 2.4508 \\
E3 & 188.2 & 272.93 & 15.96 & 19.059 & -84.73 & -3.099 \\
E4 & 167.77 & 206.48 & 14.56 & 17.599 & -38.71 & -3.039 \\
Average & $\mathbf{3 5 9 . 4 2}$ & $\mathbf{4 0 0 . 7 4}$ & $\mathbf{2 1 . 9 4 3}$ & $\mathbf{1 6 . 8 5}$ & $\mathbf{5 . 3 7 7 8}$ & $\mathbf{5 . 0 9 2 4}$ \\
Max & $\mathbf{6 0 8}$ & $\mathbf{5 7 6 . 5 8}$ & $\mathbf{2 7 . 4 3}$ & $\mathbf{1 9 . 0 5 9}$ & $\mathbf{5 7 . 6 0 7}$ & $\mathbf{1 0 . 3 0 2}$ \\
Min & $\mathbf{1 6 7 . 7 7}$ & $\mathbf{2 0 6 . 4 8}$ & $\mathbf{1 4 . 5 6}$ & $\mathbf{1 4 . 8 2}$ & $\mathbf{- 1 5 1 . 9}$ & $\mathbf{- 3 . 0 9 9}$ \\
\hline
\end{tabular}

The RMSE shows a performance of $5.4 \%$ and $5.1 \%$ for shear strength and deflection respectively. The average shear force, max shear force. and min. Shear force are $359.42 \mathrm{~N}, 608 \mathrm{~N}, 167.77 \mathrm{~N}$ respectively. Shear strength was recorded from the experimental data as against 400.74N, 576.76, 206.48N ANN predicted respectively. For deflection experimental data shows an average, max. and min. of $22 \mathrm{~mm}, 27 \mathrm{~mm}$ and $15 \mathrm{~mm}$, while the ANN predicted values are $17 \mathrm{~mm}, 20 \mathrm{~mm}$ and $15 \mathrm{~mm}$ respectively.

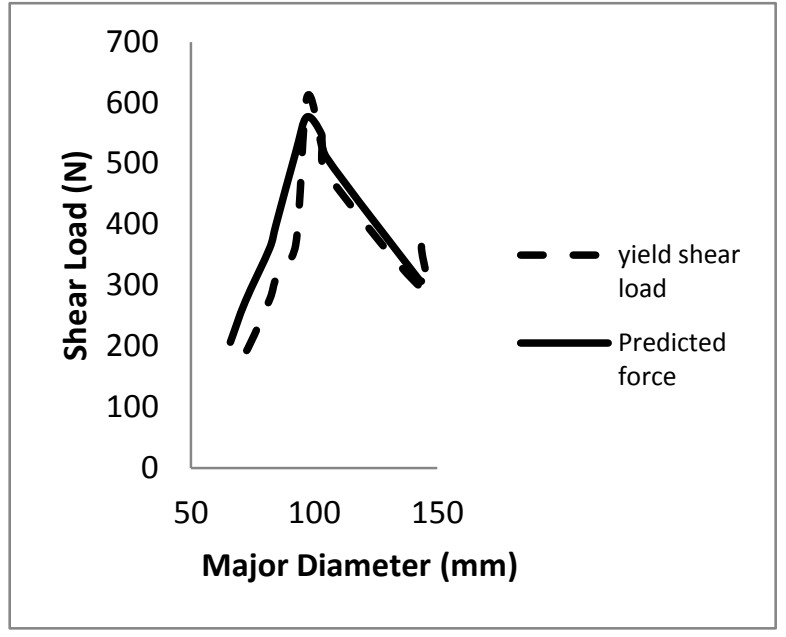

(a)

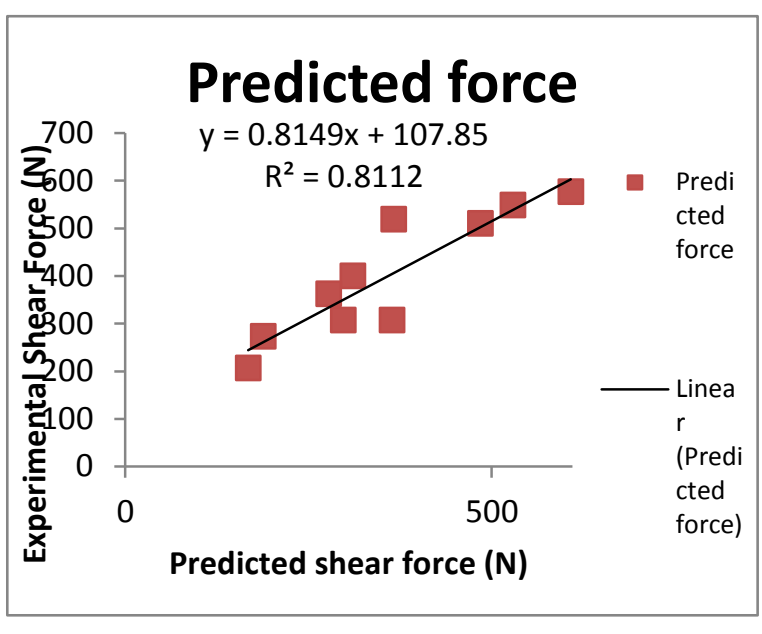

(b)

Figure 2: (a) experimental and ANN result against Major diameter, (b). Experimental versus ANN results.

Fig. 2, shows the graphical representation of the predicted and recorded shear strength. From the graph it is clear that ANN predict averagely higher shear strength values, thereby making the machine more efficient and fairly reducing the deflection at rupture. It was also observed that the RMSE values are on the high side this is because of the large deflection properties of the melon fruits.

\section{Conclusion}

The mechanical properties if of melon fruits is very necessary to design the separating, hulling and handling equipment, as well as designing harvest, post harvest handling, processing devices and transportation of the product. Also the mechanical properties is an indexes used in the determination of the quality measurement of fruits. The results show that MPL-back propagation could be an excellent tool for estimation of the mechanical properties from physical properties of high deflectable material such as melon fruits. As shown in the results (Fig 3 and Table 6). Once the optimum network architecture can be established, the network parameters (Table 2) can be set so as to minimise the prediction error made by the network. The performance of the ANN system was comparable with the measured results and it can be concluded that ANN tool can give a realistic and better estimate of the melon fruits properties. The work will facilitate the automation of melon seed processing. 


\section{Acknowledgement}

I wish to acknowledge the work of Kwaya Philip V. a master student as supervised by Prof. Mrs Z. D. Osunde, the ANN workshop, lecturer, Dr. Abiodun Musa Aibinu.

\section{References}

[1] Hayati M., Yousefi T., Ashjaee M., and Shirvang Y., Application of Artificial of Neural Network for Prediction of National Convection Heat Transfer from a Confined Horizontal Elliptical Tube. World Academy of Science, Engineering and technology, 28, 2007.

[2] Ismail A., Ashwin B. and Saurabh A., Artificial Intelligence inmechanicalengineering: A case study on vibration Analysis of cracked cantilever Beam. Proceedingsof National Conference on innovative in engineering and technology, (NACIPET2012),

[3] Kwaya P.V.; Development of Melon Seed Extractor., Unpublished M.Eng. Thesis, Federal University of Technology, Minna., M. ENG, 2008.

[4] Obodeh O. and Ajuwa C. I. (2009), Evaluation of Artificial Neural Network Performance in Predicting Diesel Engine No emissions, European Journal of Scientific research, ISSN 1450-216X, Vol. 33, No 4., (2009), Pp $642-\quad 653$. www.inTechopen.com).

[5] Seyed H. S., Javad A. K. and Rahmatollah G., Application of Artificial in the estimation of mechanical properties of materials, InTech publishers, University campus, slavka Krautzeka 83/A, Croatia,2001 (www.eurojournals.com/ejsr.htm)

[6] Svetlana I., milica J., Zorica D., Jelena P,. Slobodan D. P., Ljiljana S., and Biljana S. Artificial Neural Network in The Modelling and Optimization of Aspirin as MatrixSubstance., In AAPS PharmaSciTech, 4(1), 2003, Article 9. (www.pharmscitech.org).

[7] Turgay I., Selin S., Vebil Y. And Tarkan K. (2010), Application of artificial Neural Networks in the Prediction of Critical buckling loads of Helical Compression Spring, Journal of Mechanical Engineering, 56(6), (2010), 409-417.

\section{APPENDIX A}

\section{MATLAB NNTOOL RESULTS}
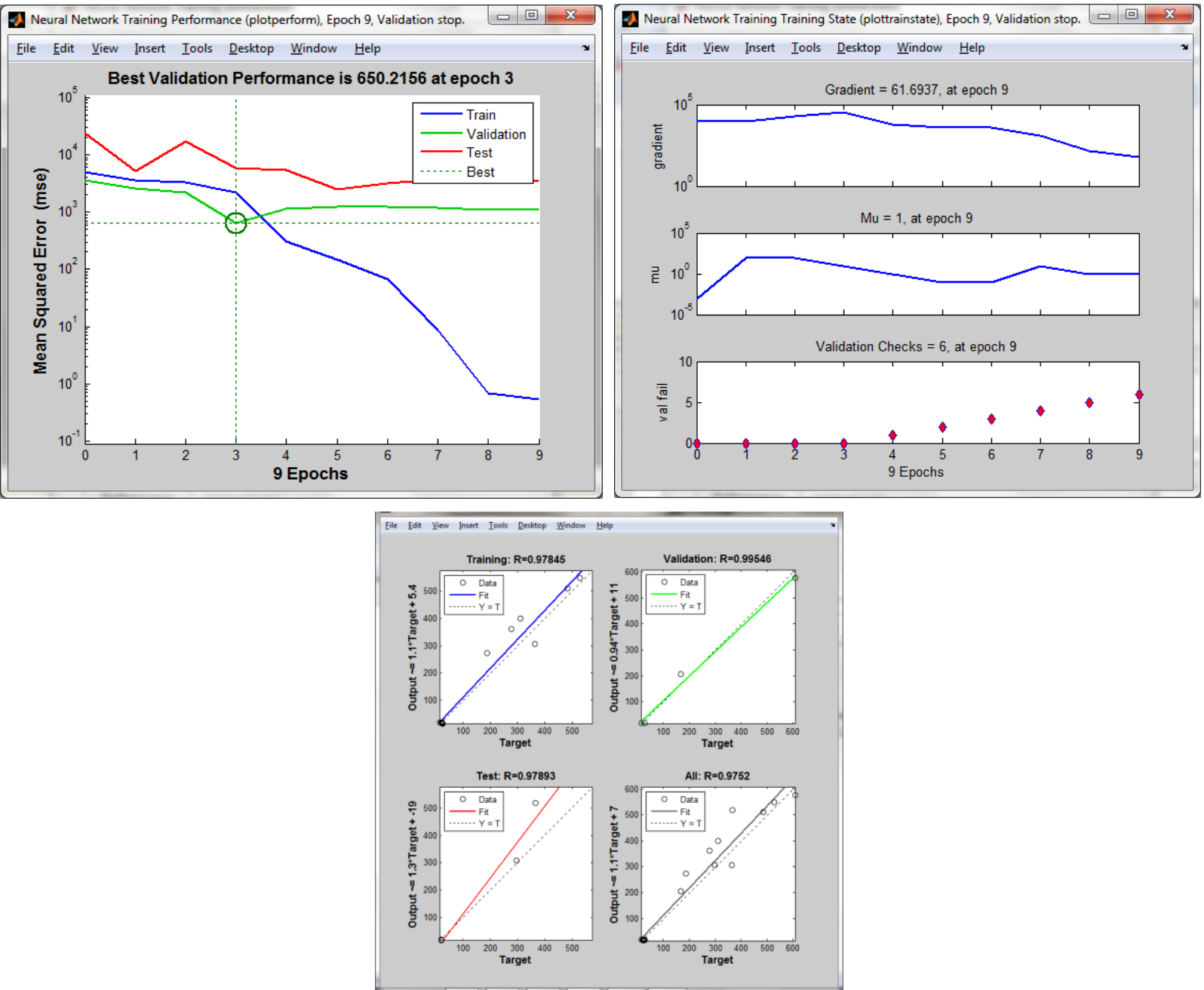

Figure 3: MATLAB Results 